\title{
Optimizing Aquaculture Chronobiology: An Inventive Marine Science
}

\section{Akbar Nikkhah*}

Chief Highly Distinguished Professor, Department of Animal Sciences, University of Zanjan, Iran

This article develops an ideology based on which circadian biology involving timing of nutrient delivery to aquaculture is of both physiological and economical importance. Due to differing endocrinological properties during different times of the circadian 24-h period, the same quality and quantity of nutrients mat be utilized with different efficiency and fate depending on when during the 24-h phase they are fed and ingested.

\section{Science Innovation and Intuitions}

Life is characterized by its circadian nature. Animals including those living in water are greatly responsive to circadian signals. Physiologically, animal endocrinology and metabolism are regulated by environmental cues through synchronizing circadian rhythms of the internal animal and those of the external environment [1]. For instance, glucose tolerance and insulin sensitivity vary in human as a diurnal animal and also in rats as nocturnal animals over the 24-h period. Glucose intolerance relatively but significantly develops as inactivity phase begins, which represents evening and night in human and morning and day-time in rats $[2,3]$.

Timing of food presentation, ingestion, fermentation, metabolism and assimilation has proved significant in manipulating and optimizing farm animals' production and health [4-7]. Aquaculture is entirely different from land life mainly in terms of nutrient and oxygen availability. As a result, different metabolic responses to varying management strategies such as different timing of nutrient delivery would be expected. Due to the extremely high growth rate in today's food-producing aquatic production systems, such responses can be considerably high and of health and economical significance.

Should hormonal responses to altered nutrient delivery to aquaculture systems change, protein synthesis efficiency will change. Thus, it is very likely that modifying circadian rhythms of nutrient consumption and metabolism via altering circadian timing of nutrient delivery to aquaculture systems will help to optimize substrate use efficiency and waste management in marine environments. Ruminant production and human health have already hosted considerable research on discovering such beneficial effects on metabolism and life quality [8-10].
Aquatic management including freshwater and marine production systems will need to develop innovative technologies to modify timing and frequency of nutrient delivery. This is to discover optimal rhythms of nutrient metabolism that yield the most efficient productive and health responses to altered circadian management approaches.

\section{Implication}

Modifying the circadian biology of aquatic production systems including timing and frequency of nutrients' peak availability is a mounting science with potential significant health, food safety and security, and economic implications.

\section{Acknowledgments}

The Iran's Ministry of Science Research and Technology, National Elite Foundation, and University of Zanjan are thanked for supporting the author's global programs of optimizing science edification in the new millennium.

\section{References}

1. Nikkhah A (2012) Eating time modulations of physiology and health: life lessons from human and ruminant models. Iran J Basic Med Sci 15: 891-899.

2. Nikkhah A (2015) Intake Circadian Physiology: An Overlooked Public Health Concern. Endocrinol Metab Synd 4: 153.

3. la Fleur SE, Kalsbeek A, Wortel J, Fekkes ML, Buijs RM (2001) A daily rhythm in glucose tolerance: a role for the suprachiasmatic nucleus. Diabetes 50 : 1237-1243.

4. Nikkhah A (2011) Ruminant chronophysiological management: an emerging bioscience. Open Access Anim Physiol 3: 9-12.

5. Nikkhah A (2013) Chronophysiology of ruminant feeding behavior and metabolism: an evolutionary review. Biol Rhythm Res 44: 197-218.

6. Nikkhah A (2014) Timing of eating a global orchestrator of biological rhythms: dairy cow nitrogen metabolism and milk fatty acids. Biol Rhythm Res 45: 661 670.

7. Nikkhah A, Furedi CJ, Kennedy AD, Crow GH, Plaizier JC (2008) Effects of feed delivery time on feed intake, milk production, and blood metabolites of dairy cows. J Dairy Sci 91: 4249-4260.

8. Nikkhah A (2012) Time of Feeding an Evolutionary Science. Lap Lambert Publishing, GmbH \& Co. KG, Germany.

9. Nikkhah A (2014) Timing of feeding: a postmodern management strategy to modulate chronophysiological rhythms in rumen fermentation kinetics. Biol Rhythm Res 45: 533-540.

10. Nikkhah A (2015) Optimizing Gestation and Early Life Physiology through Timing of Energy Turnover: Bioprocessing of Human Life. J Bioprocess Biotech 5: e125.
${ }^{*}$ Corresponding author: Akbar Nikkhah, Chief Highly Distinguished Professor, Department of Animal Sciences, Faculty of Agricultural Sciences, University of Zanjan, Zanjan, Iran, National Elite Foundation, Tehran, Iran, Tel: +98-24-350328-01; Fax: +98-24-350-332-02; E-mail: nikkhah@znu.ac.ir

Received May 17, 2015; Accepted May 20, 2015; Published May 25, 2015

Citation: Nikkhah A (2015) Optimizing Aquaculture Chronobiology: An Inventive Marine Science. J Bioprocess Biotech 5: e132 doi:10.4172/2155-9821.1000e132

Copyright: @ 2015 Nikkhah A. This is an open-access article distributed under the terms of the Creative Commons Attribution License, which permits unrestricted use, distribution, and reproduction in any medium, provided the original author and source are credited. 